\title{
Porta-enxertos influenciam o desempenho produtivo de laranjeiras-de-umbigo submetidas a poda drástica ${ }^{1}$
}

\author{
Henrique Belmonte Petry ${ }^{2}$, Bernadete Reis ${ }^{3}$, \\ Ricardo Rodrigues Silva ${ }^{4}$, Mateus Pereira Gonzatto ${ }^{5}$, Sergio Francisco Schwarz ${ }^{6}$
}

\begin{abstract}
Rootstocks influence yield performance

of navel orange trees after drastic pruning

Drastic pruning is an alternative control recommended in orchards affected by citrus canker (Xanthomonas citri subsp. citri). This study aimed at evaluating the influence of six rootstocks on growth, yield and quality of 'Monte Parnaso' (Citrus sinensis (L.) Osb.) navel oranges, after performing a drastic pruning to eradicate the citrus canker. A complete randomized blocks design, with six treatments and four replicates, was used. The following rootstocks were tested: 'Caipira' sweet orange (C. sinensis (L.) Osb.), 'Volkamer' lemon (C. volkameriana Pasq.), 'Cravo' Rangpur lime (C. limonia Osb.), 'Swingle' citrumelo (C. paradisi Macf. $\mathrm{x}$ Poncirus trifoliata (L.) Raf.), 'Sunki' mandarin (C. sunki Hort. ex Tan.) and 'Troyer' citrange (C. sinensis x P. trifoliata). Traits related to plant height, yield and fruit quality were evaluated. The largest cumulative yield was obtained from 'Cravo', 'Volkamer' and 'Sunki'. 'Cravo' and 'Volkamer' induced higher production efficiency, fruits with the highest average weight and the lowest pre-harvest fruit drop. All the evaluated rootstocks produced high quality fruits and similar canopy sizes.
\end{abstract}

KEY-WORDS: Citrus sinensis; fruit quality; citrus canker.

\section{INTRODUÇÃO}

O Brasil é o maior produtor mundial de laranjas, sendo esta a fruta mais cultivada no País, com produção anual de aproximadamente 17,55 milhões de toneladas de frutos, em 2013, e valor bruto da produção de aproximadamente 3,4 bilhões de dólares (FAO 2016). No Estado do Rio Grande do Sul, a la-

\section{RESUMO}

\begin{abstract}
A poda drástica é uma alternativa de controle recomendada para pomares onde há incidência de cancro cítrico (Xanthomonas citri subsp. citri). Objetivou-se avaliar a influência de seis porta-enxertos no crescimento, produção e qualidade dos frutos de laranjeira-de-umbigo 'Monte Parnaso' (Citrus sinensis (L.) Osb.), após a realização de poda drástica para erradicação do cancro cítrico. O delineamento foi em blocos ao acaso, com seis tratamentos e quatro repetições. Os porta-enxertos testados foram: laranjeira 'Caipira' (C. sinensis (L.) Osb.), limoeiros 'Volkameriano' (C. volkameriana Pasq.) e 'Cravo' (C. limonia Osb.), citrumeleiro 'Swingle' (C. paradisi Macf. $\times$ Poncirus trifoliata (L.) Raf.), tangerineira 'Sunki' (C. sunki Hort. ex Tan.) e citrangeiro 'Troyer' $(C$. sinensis $\times$ P. trifoliata $)$. Foram avaliadas variáveis referentes ao tamanho das plantas, produção e qualidade dos frutos. A maior produção acumulada foi obtida com 'Cravo', 'Volkameriano' e 'Sunki'. 'Cravo' e 'Volkameriano' induziram maior eficiência produtiva, frutos de maior massa média e menor queda de frutos pré-colheita. Todos os porta-enxertos induziram produção de frutos de alta qualidade e tamanhos de copa semelhantes.
\end{abstract}

PALAVRAS-CHAVE: Citrus sinensis; qualidade de fruto; cancro cítrico.

ranjeira-de-umbigo 'Monte Parnaso' (Citrus sinensis (L.) Osb.) é uma cultivar importante por produzir frutos grandes e de maturação tardia, com colheita entre os meses de agosto e outubro, época em que atinge alto valor de mercado (Oliveira et al. 2010).

A pouca diversificação no uso de porta-enxertos torna a citricultura vulnerável ao surgimento de novas pragas e doenças. O porta-enxerto limoeiro 'Cravo'

1. Trabalho recebido em ago./2015 e aceito para publicação em dez./2015 (http://dx.doi.org/10.1590/1983-40632015v4537005).

2. Empresa de Pesquisa Agropecuária e Extensão Rural de Santa Catarina, Estação Experimental de Urussanga, Urussanga, SC, Brasil.E-mail: henriquepetry@epagri.sc.gov.br.

3. Cooperativa Mista de Produção, Industrialização e Comercialização de Biocombustíveis do Brasil, Seberi, RS, Brasil.

E-mail: dete728@hotmail.com.

4. Confederação Sicredi, Porto Alegre, RS, Brasil.E-mail: rico79@terra.com.br.

5. Universidade Federal do Rio Grande do Sul, Estação Experimental Agronômica, Eldorado do Sul, RS, Brasil. E-mail:mpgonzatto@gmail.com.

6. Universidade Federal do Rio Grande do Sul, Departamento de Horticultura e Silvicultura, Porto Alegre, RS, Brasil. E-mail:schwarz@ufrgs.br. 
(C. limonia Osb.) é o mais utilizado para a produção de mudas de citros, no Brasil (Koller \& Soprano 2013). No entanto, no Rio Grande do Sul, devido aos invernos mais rigorosos, utiliza-se, predominantemente, como porta-enxerto, o 'Trifoliata' (Poncirus trifoliata (L.) Raf.) (Souza et al. 2010).

A seleção de porta-enxertos alternativos e eficientes é muito importante para a citricultura brasileira, pois pode tornar os pomares menos vulneráveis ao surgimento de novas pragas que possam afetar as poucas variedades de porta-enxertos atualmente utilizadas. Os porta-enxertos afetam mais de 20 características hortícolas dos citros, entre elas a produtividade, qualidade dos frutos, longevidade, vigor das plantas e suscetibilidade e resistência a pragas (Schäfer et al. 2001a, Souza et al. 2010).

As laranjeiras-de-umbigo são suscetíveis ao cancro cítrico (Xanthomonas citri subsp. citri). Esse patógeno é de ocorrência endêmica nos Estados do Sul do Brasil, o que dificulta a aplicação da erradicação de plantas infestadas como forma de controle (Ueno 2011). A poda drástica, associada a aplicações de produtos à base de cobre $(0,1 \%)$, é um dos métodos alternativos de erradicação do cancro cítrico, em áreas com alta incidência (Belasque Júnior et al. 2010). Essa prática deve ser recomendada em regiões onde o cancro cítrico ocorre de forma endêmica nos pomares (Belasque Júnior et al. 2005).

A poda drástica, ou de rejuvenescimento, é uma prática de recuperação de plantas decadentes, pouco vigorosas e que apresentam baixa produtividade, mas ainda com valor comercial. O uso é recomendado em plantas com idade avançada, expostas a tempestades ou ao ataque severo de pragas. A poda drástica consiste na prática de eliminar toda a vegetação da copa, deixando-se apenas o tronco com as pernadas inicias, protegendo-as, com tinta branca ou cal, de queimaduras de sol. Essa poda, quando bem-sucedida, dará retorno mais imediato, ainda que por menor tempo, se comparada à formação de um novo pomar nas mesmas condições (Silveira et al. 1992, Azevedo et al. 2013). Entretanto, pouco se conhece sobre as respostas agronômicas que os porta-enxertos conferem às cultivares-copa, após a realização desse tipo de poda.

Objetivou-se avaliar a influência de seis porta-enxertos no crescimento, produção e qualidade de frutos da laranjeira-de-umbigo 'Monte Parnaso' com sintomas de cancro cítrico, após a realização de poda drástica, nas condições edafoclimáticas da Depressão Central do Rio Grande do Sul.

\section{MATERIAL E MÉTODOS}

O estudo foi realizado com laranjeira-de-umbigo 'Monte Parnaso' (C. sinensis (L.) Osb.) enxertada sobre seis porta-enxertos, em um pomar experimental situado em área com pomares comerciais de citros, no município de Butiá (RS) (3007'12”S, 51 57'45”W e altitude de $35 \mathrm{~m}$ ). O solo da área é classificado como Argissolo Vermelho distrófico e o clima é do tipo Cfa, segundo a classificação de Köppen.

O pomar foi instalado em julho de 1996, com espaçamento de plantio de $2,5 \mathrm{~m}$ entre as plantas e 6,0 m entre as linhas, em delineamento de blocos ao acaso, com seis tratamentos e quatro repetições. Cada parcela foi constituída por quatro plantas na linha de cultivo. Os tratamentos incluiram os seguintes porta-enxertos: laranjeira 'Caipira' (C. sinensis (L.) Osb.), limoeiros 'Volkameriano' (C. volkameriana Pasq.) e 'Cravo' (C. limonia Osb.), citrumeleiro 'Swingle' (C. paradisi Macf. $\times$ P. trifoliata (L.) Raf.), tangerineira 'Sunki' (C. sunki Hort. ex Tan.) e citrangeiro 'Troyer' $(C$. sinensis $\times$ P. trifoliata $)$.

Antes do plantio, o solo foi preparado e corrigido com calcário e fósforo, conforme necessidade apontada em análise de solo previamente realizada. Os tratos culturais de manutenção, como adubação, controle de plantas daninhas e pragas, foram uniformes em todas as parcelas. Os tratos realizados foram duas roçadas anuais nas entrelinhas, duas aplicações de herbicida (glifosato; $4 \mathrm{~L} \mathrm{ha}^{-1}$ ) nas linhas de cultivo e duas aplicações (março e agosto) de NPK (SBCS 2004).

Em 1998, foi instalado um quebra-vento de Pinus ellioti no lado leste do pomar, sendo que, no lado norte, já havia duas linhas de abacateiros (Persea americana), que funcionaram como quebra-vento. Em 1999, foi constatada a incidência de cancro cítrico no pomar experimental e, por isso, em 2001, as plantas foram podadas drasticamente e receberam pulverizações de cúpricos $(0,15 \%$ de cobre metálico) a cada 21 dias, entre os meses de setembro e abril, de acordo com Reis et al. (2008). A partir de 2002, para o controle do cancro cítrico, foram realizadas, anualmente, cinco aplicações de produtos cúpricos, na concentração de $0,15 \%$ de cobre metálico, sendo três delas realizadas para proteção dos principais surtos vegetativos (setembro, novembro/dezembro e fevereiro) e outras duas nos intervalos de brotações, para proteção dos frutos jovens. Outros fungicidas, principalmente carbendazim, manzate e tebuconazo- 
le, nas suas dosagens recomendadas para a cultura dos citros, foram utilizados durante o período de florescimento e frutificação das laranjeiras, para controle da verrugose (Elsinoë fawcetti e E. australis), podridão-floral (Colletotrichum acutatum) e pinta-preta dos citros (Guignardia citricarpa). Também foram realizadas duas aplicações anuais de fosfito de potássio, para prevenção da incidência de gomose, causada por Phytophthora sp.

A produção por planta, em cada tratamento, foi quantificada pela pesagem e contagem (NF) dos frutos, nas colheitas realizadas no mês de setembro, entre os anos de 2004 e 2009. Calculou-se a produção acumulada (PA) para todos os anos avaliados. No dia da colheita, foi contado, também, o número de frutos caídos pré-colheita (NFC), por planta, nos anos de 2008 e 2009. A partir desses dados, determinou-se a porcentagem de queda pré-colheita de frutos (QPF), pela seguinte equação: $\mathrm{QPF}=(\mathrm{NFC} /(\mathrm{NF}+\mathrm{NFC}) \mathrm{x}$ 100. Posteriormente, foi calculada a média da QPF dos dois anos avaliados.

Determinou-se a qualidade de uma amostra de 10 frutos por parcela, sendo avaliadas as seguintes variáveis: massa média dos frutos (MMF), expressa em gramas por fruto; teor de suco (TS), expresso em porcentagem, pela equação $\mathrm{TS}=$ (massa do suco/massa total da amostra) x 100; teor de sólidos solúveis totais (SST), determinado por refratometria e expresso em ${ }^{\circ}$ Brix; acidez total titulável (ATT), expressa em percentual de equivalente em ácido cítrico, pela titulação de cerca de $6 \mathrm{~g}$ de suco com solução de $\mathrm{NaOH} 0,1 \mathrm{~N}$, até ser atingido $\mathrm{pH}$ de 8,1 , pela equação $\mathrm{ATT}=[(\mathrm{mL}$ de $\mathrm{NaOH}) \times($ concentração de $\mathrm{NaOH}) \times$ $0,064 \times 100] /($ gramas de suco); e relação SST/ATT (ratio) (AOAC 2000).

Em dezembro de 2009, foi calculado o volume de copa (VC) e a área de projeção da copa (APC), após a medição dos diâmetros transversal (DT) e longitudinal (DL) da copa (em relação à linha de plantas) e da altura (h) das plantas, pelas equações $\mathrm{VC}=(\pi / 6) \times \mathrm{h} \times \mathrm{DT} \times \mathrm{DL}($ Zekri 2000) e APC $=\pi$ $(\mathrm{DL}+\mathrm{DT} / 4)^{2}$ (Reis et al. 2008).

Também foi calculado o diâmetro do tronco $(\varnothing$ tronco), pela equação $\varnothing$ tronco $=$ perímetro do tronco/ $\pi$, e a eficiência produtiva (EP) foi estimada dividindo-se a PA pelo VC de cada planta (Georgiou 2009, Catuarias-Avilés et al. 2011).

O índice de alternância da produção (IAP) foi calculado entre os anos de 2004 e 2009, utilizando-se a seguinte equação: IAP $=1 / \mathrm{n}-1 \times\{|(\mathrm{a} 2-\mathrm{a} 1)| /(\mathrm{a} 2+$ $\mathrm{a} 1)+|(\mathrm{a} 3-\mathrm{a} 2)| /(\mathrm{a} 3+\mathrm{a} 2)+\ldots+|(\mathrm{a}(\mathrm{n})-\mathrm{a}(\mathrm{n}-1))| /$ $(\mathrm{a}(\mathrm{n})+\mathrm{a}(\mathrm{n}-1))\}$, em que $\mathrm{n}=$ número de anos e $\mathrm{a} 1$, $\mathrm{a} 2, \ldots, \mathrm{a}(\mathrm{n}-1), \mathrm{a}(\mathrm{n})=$ produção dos anos correspondentes (Stenzel et al. 2003). O IAP pode variar de $0 \mathrm{a}$ 1. Valor de IAP superior a 0,5 indica que há tendência de alternância de produção, e inferior a 0,5 indica que as plantas apresentam tendência de safras regulares ao longo dos anos (Bassal 2009).

Os dados referentes às variáveis de crescimento, produção e qualidade dos frutos foram submetidos à análise de variância e as médias comparadas pelo teste de Scott-Knott $(\mathrm{p} \leq 0,05)$ (Borges \& Ferreira 2003). Foi realizado o teste de correlação simples de Pearson entre os dados obtidos para volume de copa e eficiência produtiva das laranjeiras. O Programa estatístico utilizado foi o Assistat 7.7 beta.

\section{RESULTADOS E DISCUSSÃO}

Não foram observadas diferenças para a altura de planta (h), área de projeção da copa (APC), volume de copa (VC) e diâmetro de tronco ( $\varnothing$ tronco) de laranjeira-de-umbigo 'Monte Parnaso' enxertada em diferentes porta-enxertos (Tabela 1), oito anos após a poda drástica para manejo do cancro cítrico. Não foram encontrados relatos sobre a resposta de plantas cítricas à poda drástica, quando enxertadas em diferentes porta-enxertos. Porém, era esperado que os porta-enxertos indutores de maior vigor à copa apresentassem maior crescimento das plantas, ao longo dos anos, o que não se verificou.

Alguns trabalhos prévios relatam diferenças no vigor de plantas cítricas induzido por porta-enxertos. Brugnara et al. (2009) encontraram diferenças no crescimento do tronco de tangerineira 'Michal', em área experimental próxima à do presente estudo, onde as plantas sobre o limoeiro 'Cravo' apresentaram maior circunferência de tronco que as plantas sobre o citrangeiro 'Troyer'. As plantas enxertadas em tangerineira 'Sunki' e citrumeleiro 'Swingle' mostraram-se intermediárias para esta variável. Naquele trabalho, os porta-enxertos não induziram diferenças quanto à altura de planta e área de projeção da copa. Também em área experimental próxima, Gonzatto et al. (2011), estudando a tangerineira 'Oneco' (C. reticulata Blanco), encontraram maior altura e circunferência de tronco nas plantas enxertadas sobre a laranjeira 'Caipira'. Este mesmo porta-enxerto, em conjunto com o citrumeleiro 'Swingle', apresentou o maior volume de copa. 
Nos anos de 2004 a 2007, a produção anual das plantas sobre os diferentes porta-enxertos não diferiu. Já no ano de 2008, a produção das plantas enxertadas sobre os limoeiros 'Cravo' e 'Volkameriano' foi superior à das plantas enxertadas sobre os demais porta-enxertos, sendo que o citrumeleiro 'Swingle' e o citrangeiro 'Troyer' induziram as menores produções. Em 2009, as plantas enxertadas sobre a tangerineira 'Sunki' e o limoeiro 'Cravo' tiveram as maiores produções, em relação aos demais tratamentos. A produção acumulada foi superior nas plantas enxertadas sobre os porta-enxertos 'Sunki', 'Cravo' e 'Volkameriano' (Tabela 2).

Em um experimento no noroeste do Estado do Paraná (Auler et al. 2008), a tangerineira 'Sunki', em dez safras avaliadas, se destacou como porta-enxerto para a laranjeira 'Valência', proporcionando maior produção acumulada que 'Cravo', 'Troyer'

Tabela 1. Altura (h), área de projeção da copa (APC), volume da copa (VC) e diâmetro do tronco (Ø tronco) de laranjeira-de-umbigo 'Monte Parnaso' enxertada em seis porta-enxertos, oito anos após poda drástica (Butiá, RS, 2009).

\begin{tabular}{lcccc}
\hline \multirow{2}{*}{ Porta-enxerto } & $\mathrm{h}^{\mathrm{z}}$ & $\mathrm{APC}^{\mathrm{z}}$ & $\mathrm{VC}^{\mathrm{z}}$ & $\varnothing$ tronco $^{\mathrm{z}}$ \\
\cline { 2 - 5 } & $\mathrm{m}$ & $\mathrm{m}^{2}$ & $\mathrm{~m}^{3}$ & $\mathrm{~cm}$ \\
\hline 'Caipira' & 2,88 & 7,08 & 13,48 & 12,7 \\
'Volkameriano' & 2,62 & 6,72 & 11,65 & 11,5 \\
'Cravo' & 2,73 & 6,39 & 11,42 & 11,7 \\
'Swingle' & 2,71 & 6,84 & 12,24 & 10,2 \\
'Sunki' & 2,90 & 8,07 & 15,62 & 12,3 \\
'Troyer' & 3,11 & 7,77 & 15,74 & 11,7 \\
\hline Média & 2,82 & 7,10 & 13,36 & 11,7 \\
\hline CV $(\%)$ & 7,68 & 13,17 & 18,68 & 7,79 \\
\hline
\end{tabular}

${ }^{2}$ Diferenças das médias não significativas pelo teste de Scott-Knott $(\mathrm{p}<0,05)$. e 'Caipira'. Nesse mesmo estudo, a tangerineira 'Cleópatra' (C. reshni Hort. ex Tan.) e o tangeleiro 'Orlando' (C. tangerina Hort. ex Tan. x C. paradisi Macf.) também se destacaram como porta-enxertos. Georgiou \& Gregoriou (1999), avaliando laranjeira 'Shamouti' sobre 14 porta-enxertos, no Chipre, verificaram que os limoeiros 'Volkameriano' e 'Cravo' proporcionaram a maior produção acumulada, ao longo de 14 safras avaliadas. O citrangeiro 'Troyer' foi o menos produtivo e o citrumeleiro 'Swingle' induziu comportamento intermediário.

Em estudos com a laranjeira 'Folha Murcha', o melhor desempenho em produção acumulada foi em árvores enxertadas sobre limoeiros 'Cravo' e 'Volkameriano' e sobre a tangerineira 'Sunki', no noroeste do Estado do Paraná (Stenzel et al. 2005a). Por outro lado, na região norte do mesmo Estado, o melhor comportamento foi observado nos porta-enxertos limoeiro 'Rugoso da África' (C. jambhiri Lush.) e tangerineira 'Cleópatra' (Stenzel et al. 2005b). Já no Estado de São Paulo, os maiores valores de eficiência produtiva foram observados sobre o trifoliata 'Rubidoux' (Cantuarias-Avilés et al. 2011).

O índice de alternância de produção não foi influenciado pelo porta-enxerto, ao longo dos anos avaliados, tendo média de 0,37 (Tabela 2). Esse resultado aponta para uma baixa tendência de alternância de produção em laranjeira-de-umbigo 'Monte Parnaso'.

A literatura mostra resultados divergentes, em relação à existência de efeito dos porta-enxertos sobre o IAP, em copas de laranjeiras. No caso da laranjeira 'Folha Murcha', de produção tardia, observou-se efeito dos porta-enxertos sobre o IAP em dois trabalhos, em diferentes regiões do Brasil (Stenzel et al. 2005a, Cantuarias-Avilés et al. 2011). Já em laran-

Tabela 2. Produção anual e acumulada (PA), índice de alternância de produção (IAP), queda pré-colheita de frutos (QPF, média de 2008 e 2009) e eficiência de produção (EP) de laranjeira-de-umbigo 'Monte Parnaso' enxertada em seis porta-enxertos, entre três e oito anos após poda drástica (Butiá, RS, 2004 a 2009).

\begin{tabular}{|c|c|c|c|c|c|c|c|c|c|c|}
\hline \multirow{2}{*}{ Porta-enxerto } & \multicolumn{6}{|c|}{$\longrightarrow$ Produção $\left(\mathrm{kg}\right.$ planta $\left.^{-1}\right)$} & \multirow{2}{*}{$\frac{\text { PA }}{\text { kg planta }^{-1}}$} & \multirow{2}{*}{ IAP } & \multirow{2}{*}{$\begin{array}{c}\text { QPF } \\
\%\end{array}$} & \multirow{2}{*}{$\frac{\mathrm{EP}\left(\mathrm{kg} \mathrm{m}^{-3}\right)}{2009}$} \\
\hline & 2004 & 2005 & 2006 & 2007 & 2008 & 2009 & & & & \\
\hline 'Caipira' & $8,5^{\text {ns }}$ & $19,3^{\text {ns }}$ & $11,1^{\mathrm{ns}}$ & $6,2^{\mathrm{ns}}$ & $13,9 \mathrm{~b}$ & $17,2 \mathrm{~b}$ & $76,2 \mathrm{~b}$ & $0,35^{\text {ns }}$ & $35,3 \mathrm{~b}$ & $6,1 \mathrm{~b}$ \\
\hline 'Volkameriano' & 9,4 & 24,3 & 14,9 & 7,4 & $32,7 \mathrm{a}$ & $17,0 \mathrm{~b}$ & $105,7 \mathrm{a}$ & 0,41 & $32,3 \mathrm{~b}$ & 9,3 a \\
\hline 'Cravo' & 12,8 & 33,6 & 18,1 & 8,5 & $25,4 \mathrm{a}$ & $26,4 \mathrm{a}$ & $124,9 \mathrm{a}$ & 0,33 & $27,3 \mathrm{~b}$ & $10,9 \mathrm{a}$ \\
\hline 'Swingle' & 13,5 & 30,0 & 8,8 & 10,4 & $6,6 \mathrm{c}$ & $16,5 \mathrm{~b}$ & $85,7 \mathrm{~b}$ & 0,37 & $59,8 \mathrm{a}$ & $7,1 \mathrm{~b}$ \\
\hline 'Sunki' & 13,0 & 18,9 & 17,1 & 4,7 & $13,5 \mathrm{~b}$ & $26,7 \mathrm{a}$ & 93,8 a & 0,38 & $36,8 \mathrm{~b}$ & $6,4 \mathrm{~b}$ \\
\hline 'Troyer' & 8,3 & 27,4 & 9,7 & 6,0 & $7,1 \mathrm{c}$ & $11,1 \mathrm{~b}$ & $69,6 \mathrm{~b}$ & 0,36 & $52,0 \mathrm{a}$ & $4,5 \mathrm{~b}$ \\
\hline Média & 10,96 & 25,59 & 13,26 & 7,22 & 16,53 & 19,13 & 118,15 & 0,369 & 40,54 & 7,39 \\
\hline CV (\%) & 58,6 & 28,8 & 36,5 & 49,1 & 30,2 & 36,3 & 22,1 & 24,3 & 15,6 & 31,2 \\
\hline
\end{tabular}

Médias seguidas pela mesma letra, na coluna, não diferem estatisticamente entre si, pelo Teste de Scott-Knott $(\mathrm{p}<0,05)$. ${ }^{\text {ns }}$ não significativo. 
jeiras precoce, como a 'Shamouti', não se observou essa influência dos porta-enxertos (Georgiou \& Gregoriou 1999). A não observação de efeito dos porta-enxertos sobre essa característica, no presente estudo, parece estar vinculada ao fato de o período avaliado não incluir os anos iniciais de produção do pomar. O efeito diferencial dos porta-enxertos sobre o IAP, quando existente, é geralmente associado à instabilidade de produção das primeiras floradas (Gonzatto et al. 2011).

Os limoeiros 'Cravo' e 'Volkameriano' induziram maior eficiência produtiva (EP) na laranjeira-de-umbigo 'Monte Parnaso', em relação aos demais porta-enxertos testados (Tabela 2). Em outras pesquisas, Forner-Giner et al. (2003), com a laranjeira 'Navelina'; Stenzel et al. (2005a), com a laranjeira 'Folha Murcha', no noroeste do Paraná; e Auler et al. (2008), com a laranjeira 'Valência', encontraram diferenças na eficiência produtiva das plantas sobre diferentes porta-enxertos. Contrariamente, Stenzel et al. (2005b) não constataram diferenças na copa de 'Folha Murcha', no norte do Paraná. Nesses experimentos, entretanto, havia maior diversidade de cultivares porta-enxertos, incluindo a presença de genótipos mais contrastantes, quanto à indução de vigor no volume de copa, o que não ocorreu no presente trabalho (Tabela 1). Verificou-se coeficiente de correlação simples (Pearson) de -0,693 ( $p<0,01)$ entre o volume de copa e a EP, efeito esperado e já descrito em laranjeira 'Folha Murcha' (Cantuarias-Avilés et al. 2011).

As laranjeiras-de-umbigo apresentam maior dificuldade de retenção dos frutos na planta. Esse problema é acentuado na cultivar 'Monte Parnaso', provavelmente pela maior massa média dos frutos, em relação às demais laranjas-de-umbigo. Esse fato fica evidente em nosso trabalho, em que as laranjeiras apresentaram acentuada queda pré-colheita de frutos (QPF). A queda dos frutos foi afetada pelos porta-enxertos avaliados (Tabela 2), sendo que, para 'Swingle' e 'Troyer', ocorreram as maiores porcentagens de queda de frutos, na média dos dois anos avaliados. Mesmo assim, a retenção de frutos pode ser aumentada, visto que Koller et al. (1999) e Schäfer et al. (1999 e 2001b) obtiveram aumentos de até $45 \%$ na produção de frutos, com incisão anelar em ramos e/ou aplicações de reguladores de crescimento.

Em geral, a qualidade dos frutos foi satisfatória sobre todos os porta-enxertos testados, com relação SST/AAT superior a 6,5 e TS superior a $33 \%$, pa- râmetros mínimos internacionais de qualidade para o consumo in natura de laranjas-de umbigo (Oecd 2010).

Na média dos anos avaliados (Tabela 3), não houve efeito dos porta-enxertos sobre o teor de suco, que foi, em média, superior a $47 \%$. A massa média dos frutos (MMF) produzidos nas plantas sobre os porta-enxertos 'Cravo' e 'Volkameriano' foi superior à verificada nos demais porta-enxertos, ao passo que, para 'Swingle' e 'Troyer', foram obtidas as menores MMF. Essa redução na massa dos frutos sobre essas cultivares não seria negativa, em termos de mercado, visto que, mesmo com a redução, a MMF foi superior a $300 \mathrm{~g}$ em todos os tratamentos.

Quanto ao teor de SST, os frutos produzidos em plantas sobre 'Swingle' e 'Troyer' acumularam os maiores teores, enquanto, sobre 'Volkameriano', obtiveram os menores valores. Já com relação à ATT, os maiores teores foram observados nos frutos de plantas enxertadas sobre 'Volkameriano' e 'Caipira', sendo que as demais combinações copa/porta-enxerto não diferiram entre si. Quanto à relação SST/ATT, os frutos das plantas enxertadas sobre 'Sunki' e 'Cravo' apresentaram relação menor que nos demais tratamentos.

Diversos trabalhos registraram efeito do porta-enxerto na qualidade dos frutos. Brugnara et al. (2009), em estudo com a tangerineira 'Michal', na mesma área experimental do presente trabalho, verificaram que o limoeiro 'Cravo' induziu à produção de frutos com menores teores de SST e ATT, porém, não diferindo dos demais na relação SST/ATT.

Tabela 3. Massa média dos frutos (MMF), teor de suco (TS), sólidos solúveis totais (SST), acidez total titulável (ATT) e relação SST/ATT de frutos de laranjeira-deumbigo 'Monte Parnaso' enxertada em seis portaenxertos, entre quatro e oito anos após poda drástica (Butiá, RS, 2005 a 2009 - média).

\begin{tabular}{lccrcr}
\hline \multirow{2}{*}{ Porta-enxerto } & MMF & TS & SST & \multicolumn{1}{c}{ ATT } & \multirow{2}{*}{ SST/ATT } \\
\cline { 2 - 5 } & $\mathrm{g}$ & $\%$ & ${ }^{\circ}$ Brix & \multicolumn{1}{c}{$\%$} & \\
\hline 'Caipira' & $334 \mathrm{~b}$ & $46,5^{\text {ns }}$ & $9,3 \mathrm{~b}$ & $0,88 \mathrm{~b}$ & $10,6 \mathrm{a}$ \\
'Volkameriano' & $365 \mathrm{a}$ & 45,6 & $8,7 \mathrm{c}$ & $0,85 \mathrm{~b}$ & $10,2 \mathrm{a}$ \\
'Cravo' & $361 \mathrm{a}$ & 47,4 & $9,1 \mathrm{~b}$ & $0,98 \mathrm{a}$ & $9,3 \mathrm{~b}$ \\
'Swingle' & $314 \mathrm{c}$ & 48,8 & $10,3 \mathrm{a}$ & $1,00 \mathrm{a}$ & $10,3 \mathrm{a}$ \\
'Sunki' & $341 \mathrm{~b}$ & 47,7 & $9,4 \mathrm{~b}$ & $0,96 \mathrm{a}$ & $9,8 \mathrm{~b}$ \\
'Troyer' & $318 \mathrm{c}$ & 46,9 & $9,9 \mathrm{a}$ & $0,93 \mathrm{a}$ & $10,6 \mathrm{a}$ \\
\hline Média & 0,3388 & 47,1 & 9,45 & 0,93 & 10,19 \\
\hline CV (\%) & 4,15 & 3,18 & 3,35 & 6,02 & 5,37 \\
\hline
\end{tabular}

* Médias seguidas pela mesma letra, na coluna, não diferem estatisticamente entre si, pelo teste de Scott-Knott $(p<0,05)$. ns não significativo. 
Stenzel et al. (2005b) verificaram que os frutos de laranjeira 'Folha Murcha' produzidos sobre o porta-enxerto 'Sunki' tiveram a maior massa média, mas os porta-enxertos 'Cravo' e 'Cleópatra' induziram maior teor de suco e os porta-enxertos 'Cravo' e 'Volkameriano' proporcionaram à variedade 'Copa' maior teor de SST.

\section{CONCLUSÕES}

1. Após poda drástica, os porta-enxertos dos limoeiros 'Cravo' e 'Volkameriano' induzem, na laranjeira-de-umbigo 'Monte Parnaso', maior eficiência produtiva, frutos de maior massa média e menor queda de frutos pré-colheita.

2. Os porta-enxertos testados não induzem diferenças no crescimento das laranjeiras-de-umbigo 'Monte Parnaso'.

3. Todos os porta-enxertos testados induzem, na laranjeira-de-umbigo 'Monte Parnaso', produção de frutos com indicadores de qualidade superiores aos padrões internacionais mínimos para laranjas.

\section{REFERÊNCIAS}

ASSOCIATION OF OFFICIAL ANALYTICAL CHEMISTS (AOAC). Official methods of analysis of the Association of Official Analytical Chemists. 17. ed. Washington, DC: AOAC International, 2000.

AULER, P. A. M.; FIORI-TUTIDA, A. C. G.; TAZIMA, Z. H. Comportamento da laranjeira 'Valência' sobre seis porta-enxertos no noroeste do Paraná. Revista Brasileira de Fruticultura, Jaboticabal, v. 30, n. 1, p. 229-234, 2008.

AZEVEDO, F. A. et al. Poda na citricultura. Citrus Research \& Technology, Cordeirópolis, v. 34, n. 1, p. 17 30, 2013.

BASSAL, M. A. Growth, yield and fruit quality of 'Marisol' clementine grown on four rootstocks in Egypt. Scientia Horticulturae, Amsterdam, v. 119, n. 2, p. 132137, 2009.

BELASQUE JÚNIOR, J.; AYRES, A. J.; GIMENESFERNANDES, N. Citrus canker sanitation in groves by drastic pruning. In: INTERNATIONAL CITRUS CANKER AND HUANGLONGBING RESEARCH WORKSHOP, 2., 2005, Orlando. Proceedings... Orlando: Florida Citrus Mutual, 2005. p. 24.

BELASQUE JÚNIOR, J. et al. Prováveis consequências do abrandamento da metodologia de erradicação do cancro cítrico no Estado de São Paulo. Tropical Plant Pathology, Viçosa, v. 35, n. 5, p. 314-317, 2010.
BORGES, L. C.; FERREIRA, D. F. Poder e taxas de erro tipo I dos testes Scott-Knott, Tukey e Student-NewmanKeuls sob distribuições normal e não normais dos resíduos. Revista de Matemática e Estatística, São Paulo, v. 21, n. 1, p. 67-83, 2003.

BRUGNARA, E. C. et al. Porta-enxertos para a tangerineira 'Michal' no Rio Grande do Sul. Ciência Rural, Santa Maria, v. 39, n. 5, p. 1374-1379, 2009.

CANTUARIAS-AVILÉS, T. et al. Horticultural performance of 'Folha Murcha' sweet orange onto twelve rootstocks. Scientia Horticulturae, Amsterdam, v. 129, n. 2, p. 259-265, 2011.

FOOD AND AGRICULTURE ORGANIZATION (FAO). FAOSTAT: database results. 2016. Disponível em: $<$ http:// faostat.fao.org>. Acesso em: 07 jan. 2016.

FORNER-GINER, M. A. et al. Performance of 'Navelina' orange on 14 rootstocks in northern Valencia. Scientia Horticulturae, Amsterdam, v. 98, n. 3, p. 223-232, 2003.

GEORGIOU, A. Evaluation of rootstocks for the Cyprus local lemon variety 'Lapithkiotiki'. Scientia Horticulturae, Amsterdam, v. 123, n. 2, p. 184-187, 2009.

GEORGIOU, A.; GREGORIOU, C. Growth, yield and fruit quality of 'Shamouti' orange on fourteen rootstocks in Cyprus. Scientia Horticulturae, Amsterdam, v. 80, n. 1-2, p. 113-121, 1999.

GONZATTO, M. P. et al. Performance of 'Oneco' mandarin on six rootstocks in South Brazil. Pesquisa Agropecuária Brasileira, Brasília, DF, v. 46, n. 4, p. 406411, 2011.

KOLLER, O. L.; SOPRANO, E. Principais cultivares cítricos. In: KOLLER, O. L.; SOPRANO, E. Citricultura catarinense. Florianópolis: Epagri, 2013. p. 57-120.

KOLLER, O. C.; FERRARI SOBRINHO, F.; SCHWARZ, S. F. Frutificação precoce de laranjeiras 'Monte Parnaso' com anelagem e pulverizações de ácido giberélico e óleo mineral. Pesquisa Agropecuária Brasileira, Brasília, DF, v. 34, n. 1, p. 63-68, 1999.

OLIVEIRA, R. P. et al. Cultivares-copa de citros. In: OLIVEIRA, R. P. et al. Produção orgânica de citros no Rio Grande do Sul. Pelotas: Embrapa Clima Temperado, 2010. p. 53-85.

ORGANISATION FOR ECONOMIC CO-OPERATION AND DEVELOPMENT (OECD). International standards for fruit and vegetables: citrus fruit. Paris: OECD Publishing, 2010.

REIS, B. et al. Produção de frutos e incidência de cancro cítrico em laranjeiras 'Monte Parnaso' enxertadas sobre sete porta-enxertos. Ciência Rural, Santa Maria, v. 38, n. 3, p. 672-678, 2008. 
SCHÄFER, G.; BASTIANEL, M.; DORNELLES, A. C. Porta-enxertos utilizados na citricultura. Ciência Rural, Santa Maria, v. 31, n. 4, p. 723-733, 2001a.

SCHÄFER, G.; KOLLER, O. C.; SARTORI, I. A. Retenção de frutos de laranjeiras-de-umbigo 'Monte Parnaso' em função da aplicação de 2,4-d, ácido giberélico e da anelagem de ramos. Ciência Rural, Santa Maria, v. 29, n. 4, p. 639-644, 1999.

SCHÄFER, G. et al. Efeito de reguladores de crescimento, aplicados em diferentes épocas, e da incisão anelar dos ramos principais sobre a produção da laranjeirade-umbigo 'Monte Parnaso'. Ciência Rural, Santa Maria, v. 31, n. 4, p. 577-581, 2001 b.

SILVEIRA, D. F.; SCHWARZ, S. F.; KOLLER, O. C. Poda de rejuvenescimento em laranjeira 'Valência' (Citrus sinensis Osb.) clone velho. Revista Brasileira de Fruticultura, Cruz das Almas, v. 14, n. 2, p. 235-238, 1992.

SOCIEDADE BRASILEIRA DE CIÊNCIA DO SOLO (SBCS). Manual de adubação e calagem para os Estados do Rio Grande do Sul e Santa Catarina. Porto Alegre: SBCS - Núcleo Regional Sul, 2004.
SOUZA, E. L. S.; SCHWARZ, S. F.; OLIVEIRA, R. P. Porta-enxertos para os citros no Rio Grande do Sul. In: SOUZA, E. L. S.; SCHWARZ, S. F.; OLIVEIRA, R. P. Indicações técnicas para a citricultura do Rio Grande do Sul. Porto Alegre: Fepagro, 2010. p. 19-29.

STENZEL, N. M. C. et al. Comportamento da laranjeira 'Folha Murcha' em sete porta-enxertos no noroeste do Paraná. Revista Brasileira de Fruticultura, Jaboticabal, v. 27, n. 3, p. 408-411, 2005 a.

STENZEL, N. M. C. et al. Desenvolvimento vegetativo, produção e qualidade dos frutos da laranjeira 'Folha Murcha' sobre seis porta-enxertos no norte do Paraná. Ciência Rural, Santa Maria, v. 35, n. 6, p. 1281-1286, 2005 b.

STENZEL, N. M. C. et al. Performance of "Ponkan" mandarin on seven rootstocks in Southern Brazil. Hortscience, St. Joseph, v. 38, n. 2, p. 176-178, 2003.

UENO, B. Doenças. In: UENO, B. Cultivo de citros sem sementes. Pelotas: Embrapa Clima Temperado, 2011. p. 229-264. (Sistema de produção, 21).

ZEKRI, M. Citrus rootstocks affect scion nutrition, fruit quality, growth, yield and economical return. Fruits, Les Ulis, v. 55, n. 4, p. 231-239, 2000. 